V Seminário Anual Científico e Tecnológico | Bio-Manguinhos

\title{
REA 02 - Biosensor-based epitope peptide screening to detect spotted fever
}

Isis Campos Prado ; Mônica Elizabeth Tatiana Alcón Chino²; Elba Regina Lemos³; André Luis Almeida Souza ${ }^{2}$; Raiane Borges Gomes ${ }^{1 *}$; Salvatore Giovanni De Simone ${ }^{4}$.

1 CDTS / Fiocruz; INCT-IDN;

2 IOC / Fiocruz, Laboratory of Experimental and Computational Biochemistry of Pharmaceuticals;

3 IOC / Fiocruz, Hantavirus and Rickettsia Laboratory;

4 CDTS / Fiocruz; INCT-IDN; UFF, Biology Institute, Department of Cell.

\section{Introduction:}

Brazilian spotted fever caused by Rickettsia rickettsii is the most important rickettsiosis and the only reportable tick-borne disease in Brazil. Its diagnosis is often treated based on clinical diagnosis and/or indirect immunofluorescence.

\section{Objective:}

The aim of this study was to using high affinity epitope peptide from the OMP H6PGA4_ RICRI, previously identified by our group, to develop a cyclic voltammetry-peptide based immunosensor for the diagnosis of the human disease.

\section{Methodology:}

The construction of an immunosensor from the use of ultra-specific epitopes identified by peptide microarray receiving elements used as capture antibody, was developed successfully. The electrochemical technique of cyclic voltammetry was performed on the detection signal generated by interaction between the peptide and the antibody circulating in blood samples. Printed electrodes of carbon and glutaraldehyde solution were used for fixing the electrode epitopes. Amperometric responses were generated by applying a potential of -0.6 to $0.6 \mathrm{~V}$, speed of $0.025 \mathrm{~V} / \mathrm{s}$, using 20 cycles of scans.

\section{Results:}

A detection limit of10 ng mL-1 and sensitivity $2.59 \mu \mathrm{A}$ were obtained, allowing proper clinical diagnosis. The performance of the assay was evaluated using human serum samples from infected and healthy patients. The accuracy was demonstrated by the analysis of 20 cycles of scanning and the performance against sera of healthy individuals. 
The peptide-immunosensor chip was reproducible with a coefficient of variation $\leq 10,1 \%$. The sensitivity of serum dilution was 1: 100 .

\section{Conclusion:}

The IgG biosensor-peptide test has high sensitivity, and, because it is quick and easy to perform, would be good screening test for acute spotted fever infection. IgG peptidebiosensor has good specificity, and is comparable with the ELISA -peptide and is able to identify in real time circulating antibodies. The construction of this immunosensor, able to identify in real time specific antibodies can be applied in the diagnosis of other infectious and parasitic diseases.

Keywords: Spotted fever; Epitopes; Immunosensor amperometric 